\title{
Evaluation of the possibility of separating commercial phenol from the phenolic fraction of coal tar
}

\author{
Y.O. Schastnyy ${ }^{1}, N . A$. Romanova $^{1}$, and R.R. Gizatullin ${ }^{2}$ \\ ${ }^{1}$ Department of ATPP, Department of Mineral Processing, Saint Petersburg Mining University, Saint \\ Petersburg Russia \\ ${ }^{2}$ Well Drilling Department, Department of Oil and Gas,Saint Petersburg Mining University, Saint \\ Petersburg Russia
}

\begin{abstract}
This article is about the possibility of concentrating commercial coal phenol with a concentration of $99 \%$ by the weight method of rectification from the phenolic fraction of coal tar. The sufficiency of phenol is ensured by the kumol method, however, the consumption of phenol increases. Modeling of the vapor-liquid equilibrium of double and triple mixtures of components using the NRTL model showed the presence of the following positive homogeneous azeotropic mixtures: phenolindane, phenol-indene. Modeling of the vapor-liquid equilibrium of double and triple mixtures of components using the NRTL model showed the presence of the following positive homogeneous azeotropic mixtures: phenol-indane, phenol-indene. The compositions and temperatures of these azeotropes are determined. The authors propose the isolation of phenol from the fraction and its purification from indane and indene by a clear rectification method. The technological scheme consisting of four devices is based on the analysis of the component composition of the initial mixture and the existing azeotropes. Modeling of the technological scheme showed that this scheme provides the release of phenol by $99 \%$ of the mass, which meets the requirements for coal phenol. After optimizing the technological parameters of the distillation columns, the estimated extraction costs will amount to $5.64 \mathrm{Gcal}$ per ton of commercial phenol.
\end{abstract}

\section{Introduction}

Coal tar is a by-product of metallurgical coke or oil coke production. There are many works devoted to an increased yield and improved quality of needle coke [1-5]. Coal tar has a complex composition with a high level of valuable aromatic compounds, like phenol, naphthalene, anthracene, etc. [6].Due to its content, coal tar can be used as a rich sourcefortheextraction of its components [7]. During processing by theclassical method, coal tar is separated by rectification into several fractions, which are called by the prevailing target products: light, phenolic, naphthalene, absorption, and anthracene fractions. $[8,9]$.

The most promising issue for research is the processing of phenolic and naphthalene fractions since phenol and naphthalene are valuable raw materials for chemical synthesis. 
Phenol is widely used in the manufacture of dyes, plasticizers, polymer masses, as an agent in selective oil purification, etc. Generally, basic industrial needs in phenol are satisfied by the cumene process, which converts isopropylbenzene to synthesize phenol and acetone [10]. Russia has several large petrochemical plants with phenol production facilities, located in cities such asUfa, Kazan, Samara [11,12].

However, the demand for phenol keeps growing, therefore, its separation from coal tar has practicalinterest.Although, it should be notedthat oil and coal phenols have different degrees of purity, both in terms of the content of the main component and the required profile of possible impurities.

Currently, the separation of coal tar is conducted by distillation into fractions, and the pure phenol is obtained by extraction or by chemical methods [13-18]. The same methods are used to isolate phenol from petroleum resins. Initially, coal resin (or petroleum resin) is distilled in a distillation column, then crude phenol is isolated from phenolic fraction, from which pure phenol is extracted at the next stage using selective solvents or chemical reagents, converting phenol into phenolates. The extraction method allows obtaining phenol of sufficient purity (according to GOST 11311-76 "CoalPhenol" in Russia). However, these methods are still multi-stage, expensive, and make it difficult (harder) to solve the environmental problems associated with the treatment of large amounts of wastewater. Several works are devoted to the problem of wastewater treatment from phenol [19]

Sometimes the crystallization method is used to increase the purity of commercial phenol.

In this article, the authors do not investigate the process of phenol separation from coal tar by extraction method, because this technology is well-studied and widely known. The authors suggest the separation of phenol from the fraction and its purification from indane and indene using a precision fractional distillation method. Distillation is currently used to separate the so-called crude phenol from coal tar, which is not sufficiently pure, and the subsequent additional purification is carried out by the above-mentioned extraction method.

The article suggests a phenol separation technology that meets GOST 11311-76 "Coal phenol" (government standard) with a basic substance content of at least $99 \%$ wt. This technology does not require the use of extraneous agents, except for the available water, and in terms of energy consumption, it is commensurate with the energy consumption in the separation of contaminated dirty crude phenol.

\section{Main part}

Extraction of phenol from coal tar may pose difficulties, mostly, since tar is a polyazeotropic mixture of aromatic and other compounds, including heterocyclic ones. Such azeotropic mixtures as phenol-indane and phenol-indene make the concentration of the target component more complicated and expensive. Table1 shows the composition of the initial phenolic fraction. The composition of coal tar given in the article is the result of averaging the compositions of various resins at the contracting enterprise. The name of the company is a trade secret and cannot be disclosed.

Table 1.Feed composition*.

\begin{tabular}{lcc}
\hline Components & Boiling temperature, $\mathrm{C}^{\circ}$ & Mass, $\%$ \\
\hline P-xylene & 138.4 & 0.155 \\
M-xylene & 139.1 & 0.155 \\
1-methyl-3- & 161.3 & 5.660 \\
ethylbenzene & & \\
Mesitylene & 164.7 & 2.332
\end{tabular}


Pseudocumene

Hemimellitene

Indan

Phenol

Indene

Benzonitrile

O-cresol

Durol

P-cresol

M-cresol

Prehnitene

Xylenol

Naphthalene

Thionaphthene

Methylnaphthalene
169.3

176.1

178.0

181.0

182.8

188.0

191.0

196.9

201.9

202.0

205.0

216.9

217.0

219.9
1.244

2.021

2.971

33.670

15.845

6.284

3.961

0.606

7.922

14.854

0.606

0.031

1.571

0.078

0.031

* The average composition of the phenolic fraction of coal tar

Analysis of the composition showed that phenol forms binary and ternary azeotropeswithindane and indene, naphthalene, pseudocumene, hemimellitene, mesitylene, and other compounds.Table 2 presents binary azeotropesandTable 3 presents ternary azeotropes.

Table 2.Binaryazeotropes.

\begin{tabular}{|c|c|}
\hline Components & Boilingtemperature, $\mathrm{C}^{\circ}$ \\
\hline Phenol- mesitylene & 163.62 \\
\hline Phenol-pseudocumene & 167.22 \\
\hline O-cresol-pseudocumene & 169.36 \\
\hline Phenol-indane & 171.29 \\
\hline Phenol-hemimellitene & 171.43 \\
\hline O-cresol-hemimellitene & 175.09 \\
\hline Indane- o-cresol & 175.47 \\
\hline Phenol-indene & 175.98 \\
\hline Indane- $\mathrm{p}$-cresol & 177.46 \\
\hline Indane- m-cresol & 177.50 \\
\hline Indene-o-cresol & 181.20 \\
\hline Indene-p-cresol & 182.78 \\
\hline Indene-m-cresol & 182.78 \\
\hline Benzonitrile-hemimellitene & 191.78 \\
\hline O-cresol-benzonitrile & 193.06 \\
\hline Naphthalene-p-cresol & 200.91 \\
\hline Naphthalene-m-cresol & 201.19 \\
\hline Naphthalene-xylenol & 211.12 \\
\hline
\end{tabular}

Table 3. Ternary azeotropes.

$\begin{array}{lll}\text { Components } & \text { Type of azeotrope } & \text { Boiling }\end{array}$

temperature, $\mathrm{C}^{\circ}$

$\begin{array}{cl}\text { Phenol-Indane-hemimellitene } & \text { Heterogeneous } \\ 171.27 & \\ \text { Phenol-Benzonitrile-Mesitylene } & \text { Homogeneous } \\ 191.00 & \\ \text { Benzonitrile-hemimellitene -o-cresol } & \text { Homogeneous } \\ 191.12 & \end{array}$


Benzonitrile-hemimellitene-p-cresol 91.58

Benzonitrile-hemimellitene-m-cresol 91.59
Homogeneous

Homogeneous

Separation of such mixtures by conventional distillation is a complicated task, which, as a rule, requires special methods with PSD-technologies, described in detail in the articleEnergy optimization of multi-column rectification complexes. [20] or special separating agents. The azeotropic distillation process is described in the bookProcesses and devices of oil and gas processing and petrochemistry[21]. For example, a suitable agent that satisfies this requirement is water. Water is known to form an azeotropic mixture with phenol;this fact is widely used in the separation of phenol from alpha-methylstyrene in the above-mentioned cumene method.

Calculations showed that azeotropic mixtures of phenol-indane and phenol-indene are most problematic in terms of separation. Their type, composition, and boiling points are given in the table below.

Table 4.Existing azeotropes.

\begin{tabular}{|c|c|c|c|c|c|}
\hline \multicolumn{3}{|l|}{ Phenol-Indan } & \multicolumn{3}{|c|}{ Phenol-Indene } \\
\hline \multicolumn{2}{|c|}{ Type:homogeneous } & Positive with boiling & \multicolumn{2}{|c|}{ Type: homogeneous } & Positive with \\
\hline \multicolumn{3}{|c|}{ temperature $171.29 \mathrm{C}^{\circ}$} & \multicolumn{3}{|c|}{ temperature $175.98 \mathrm{C}^{\circ}$. } \\
\hline Component & Mole ratio & Mass ratio & Component & Mole & ratio \\
\hline \multicolumn{6}{|c|}{ Mass ratio } \\
\hline $\begin{array}{l}\text { Phenol } \\
0.442\end{array}$ & 0.4011 & 0.3478 & Phenol & 0.4944 & \\
\hline $\begin{array}{l}\text { Indan } \\
\\
0.557\end{array}$ & 0.5989 & 0.6522 & Indene & 0.5056 & \\
\hline
\end{tabular}

The listed azeotropic mixtures are insensitive to pressure changes;asshowninFigure 1 forthephenol-indane mixture. To break problematic azeotropes, it is proposed to use water as a separating agent. Water forms a positive homogeneous azeotrope with phenol and can be further separated from the target product by vacuum distillation.Figure2shows equilibrium curves for the phenol-water system at normal pressure and residual pressure 20 $\mathrm{mmHg}$.

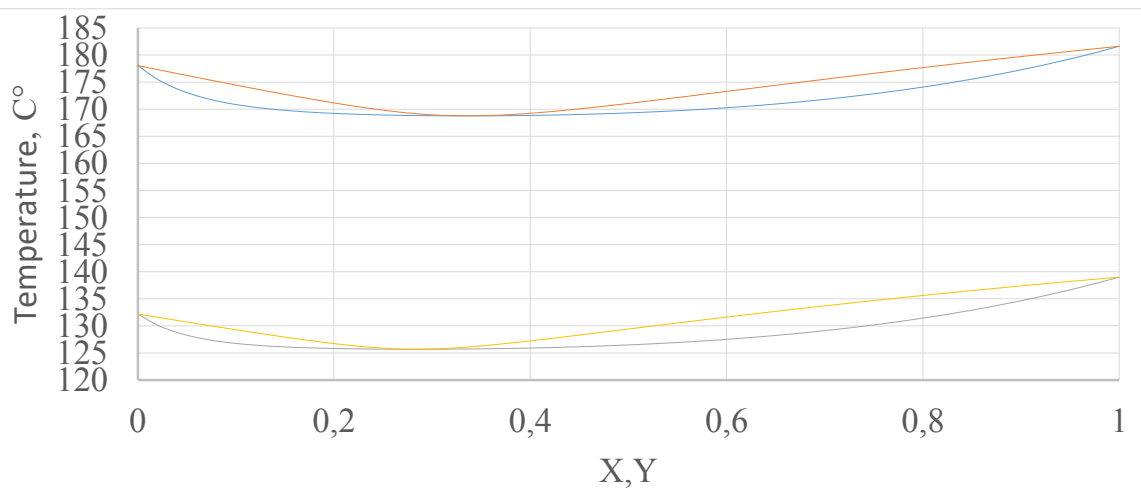

Fig. 1. The equilibrium curve in $T$-X Y coordinates for a pair of phenyl-indane at normal pressure and residual pressure in the apparatus of $200 \mathrm{mmHg}$. 


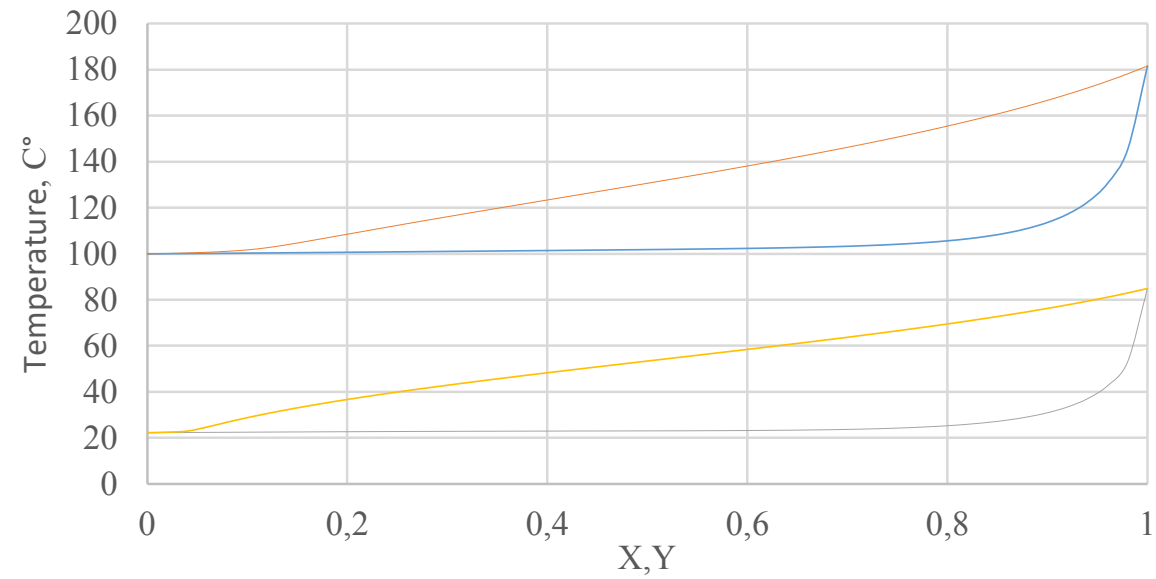

Fig. 2. The equilibrium curve in T-XY coordinates for the phenol-water pair at normal pressure and at residual pressure in the apparatus of $20 \mathrm{mmHg}$.

The separation scheme proposed herein consists of four successive distillation columns, $(\mathrm{K}-1 \ldots \mathrm{K}-4)$, the first three operate under vacuum, and the fourth is under excess pressure.

The supply stream is fed to the K-1 column that separates light impurities with boiling points lower than the boiling point of azeotropic mixtures of phenol-indane and phenolindene, such as p-xylene, m-xylene, 1-methyl-3-ethylbenzene. The bottoms product of the $\mathrm{K}-1$ column together with water $-75 \%$ of the total mass to be separated -isfed to the K-2 column, which is designedto breakphenol-indane and phenol-indeneazeotropes. Indane and indene leave the K-2 column as a distillate, while the bottom product of the K-2 column - a new phenol-water azeotrope - is fed to the K-3 column. The latter operates at a residual pressure of $20 \mathrm{~mm} \mathrm{Hg}$ and is designed to separate water. The K-4 column is used to separate commercial phenol from heavy impurities.

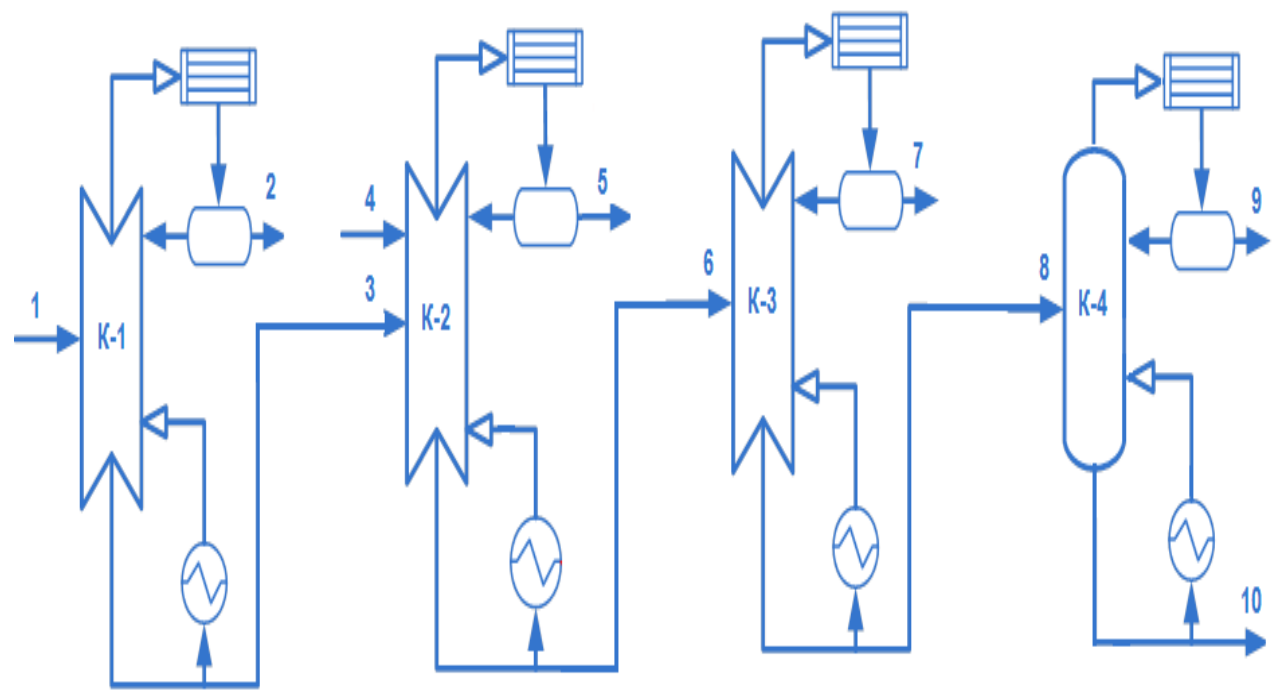

Fig. 3. Basic technological scheme of the process 
The main flows of the scheme are explained below:

1. Raw supply

2. Light components

3. Fortified fraction

4. Water

5. Indane, indene

6. Phenol-water with a heavy residue

7. Water for regeneration

8. Phenol and heavy components

9. Phenol byGOST-11311-76

10. Heavy residue

To simulate the process, the authors used the ASPENHYSYS softwarewith the NRTL thermodynamic package; the missing binary coefficients were calculated by the UNIFAC method. The main technological parameters for operations of all column units are listed inTable 5 .

Table 5. Technological parameters.

\begin{tabular}{|c|c|c|c|c|c|c|c|}
\hline \multirow{2}{*}{$\frac{\text { Column }}{\text { NTR }}$} & \multirow[t]{2}{*}{$\mathrm{K}-1$} & \multicolumn{3}{|c|}{$\mathrm{K}-2$} & \multirow[t]{2}{*}{ K-3 } & \multicolumn{2}{|c|}{ K-4 } \\
\hline & & 20 & & 15 & & 20 & 40 \\
\hline Feedstage (topdown) & & 9 & & 9 & & 10 & 20 \\
\hline $\begin{array}{l}\text { Pressure at the top. } \\
2200\end{array}$ & & 250 & & 200 & & 20 & \\
\hline mmHg. & & & & & & & \\
\hline Refluxratio & & 12 & & 4 & & 1 & 7 \\
\hline $\begin{array}{c}\text { Sampling ratio } \\
0.55\end{array}$ & & 0.12 & & 0.32 & & 0.49 & \\
\hline $\begin{array}{c}\text { Heatinput.Gcal/t* } \\
1.04\end{array}$ & & 0.39 & & 2.25 & & 1.96 & \\
\hline
\end{tabular}

*Calculation per 1 ton of commercial phenol

The table shows that the energy costs in the proposed separation scheme will amount to $5.64 \mathrm{Gcal} / \mathrm{t}$.

Thus, the following conclusions can be made:

-The result is that it is possible to separate the phenol from the resin by distillation at $99 \%$ by weight of the main substance without using extraction stages.

- Simulationof the vapor-liquid equilibrium of the initial mixture showed that there are homogeneous positive azeotropic mixtures of phenol-indane (at $760 \mathrm{~mm} \mathrm{Hg}$, the composition is equal to $0.3478 \mathrm{wt}$ of phenol and $0.6522 \mathrm{wt}$ of indane) and phenol-indene (at $760 \mathrm{~mm} \mathrm{Hg}$,thecomposition is equal to $0.4421 \mathrm{wt}$ of phenol and $0.5579 \mathrm{wt}$ of indene).

- The authorsproposeda principal schemeofdistillationof commercial coal phenol with a concentration of $99 \% \mathrm{wt}$. The separating agent to break azeotropic mixtures is water $-75 \%$ of the total coal tar to be separated.

- The scheme is optimized in terms of minimum energy costs, which amount to 5.64 $\mathrm{Gcal} / \mathrm{t}$ of commercial phenol.

\section{References}

1. V. Y. Bazhin Change in the thermoplasticity of low-grade coal in the selective extraction of metals. Journal of Mining Institute, 220, 578-581 (2016) 
2. V. Y. Bazhin Application of heat flow calorimetry for the development of mathematical models of coal coking processes. Coke and chemistry, 7, 25-29 (2015)

3. R. Y. Feshchenko, O. O. Erokhina, A. L. Kvanin, D. S. Lutskiy, V. V. Vasiliev Analytical review of the foreign publications about the methods of the rise of operating parameters of cathode blocks during 1995-2014. CIS Iron and Steel Review, 13, 48-52 (2017)

4. R. Y. Feshchenko, O. O. Erokhina, V. L. Ugolkov, M. Y. Shabalov, V. V. Vasiliev Thermal analysis of coal ash. Coke and Chemistry, 1, 17-22 (2017)

5. V. R. Kabirov, D. V. Gorlenkov, R. Y. Feshchenko, E. A. Kochetkova, M. O. Silivanov Applications of vacuum rectification for energy optimization of the fractional facility of benzene and toluene. Journal of Physics: Conference Series, 1313, $1-5(2019)$

6. S. A. Semenova, O. M. Gavrilyuk, Y. F. Patrakov Analysis of the component composition of coal coking resin group fractions. Bulletin of the Kuzbass state technical University, 5, 135-139 (2010)

7. V. I. Lobzin, S. V. Mochalnikov, G. A. Solodov, A. V. Nevedrov, A. V. Papin Production of target commercial products by deep processing of coal tar fractions. Proceedings of Tomsk Polytechnic University, 301(2), 149-151 (2007)

8. O. N. Pavlovich Composition, properties, and prospects of coal tar processing: educational electronic text edition. (Yekaterinburg: Publishing house GOU VPO UGTU-UPI, 2006)

9. I. A. Oshchepkov, I. M. Zinchenko Features of coal tar formation and processing. Bulletin of the Kuzbass state technical University, 2, 78-82 (2009)

10. V. M. Zakoshansky Alternative technologies for obtaining phenol. Russian Chemical Journal, 52(4), 53-71 (2008)

11. M. I. Baykenov, S. K. Amerkhanova, G. G. Baykenova, R. M. Slepov, A. E. Toktybaeva Extraction and cavitation extraction of phenols from coal tar. Solid fuel chemistry 1, 28p. (2013)

12. V. M. Zakoshansky Cumene process for the production of phenol-acetone. Petrochemistry, 47(4), 301-314 (2008)

13. E. Rigaut, M. Kleiber, C. Rioual, J. E. Diaz Process for treatment of phenol and tar acids containing oil. European patent specification. International publication number: WO 2010/100536 (10.09.2010 Gazette 2010/36), International application number: PCT/IB2010/000377, (2014)

14. Y. Zhao, X. Mao, W. Li, X. Gu, G. Wang Study on extraction phenol from coal tar with high flux centrifugal extractor. International Journal of Coal Science \& Technology, 4, 333-341 (2017)

15. T. Jiao, X. Qin, H. Zhang, W. Zhang, Y. Zhang, P. Liang Separation of phenol and pyridine from coal tar via liquid-liquid extraction using deep eutectic solvents. Chemical Engineering Research and Design, 145, 112-121 (2019)

16. T. Jiao, C. Li, X. Zhuang, S. Cao, H. Chen, S. Zhang The new liquid-liquid extraction method for separation of phenolic compounds from coal tar. Chemical Engineering Journal, 266, 148-155 (2015)

17. T. Jiao, C. Li, X. Zhuang, S. Cao, H. Chen, S. Zhang Separation of Phenolic Compounds from Coal Tar via Liquid-Liquid Extraction Using Amide-Compounds. Industrial \& Engineering Chemistry Research, 54, 2573-2579 (2015) 
18. X. Yang, B. Wang, H. Luo, S. Yan, J. Dai, Z. Bai Efficient recovery of phenol from coal tar processing wastewater with tributylphosphane/diethyl carbonate/cyclohexane: Extraction cycle and mechanism study. Chemical Engineering Research and Design, 157, 104-113 (2020)

19. S. Mohammadi, A. Kargari, H. Sanaeepur, K. Abbassian, A. Najafi Phenol removal from industrial wastewaters: a short review. Desalination and Water Treatment, 53, 2215-2234 (2014)

20. V. S. Leontiev Energy optimization of multi-column rectification complexes. Electronic scientific journal "Oil and Gas Business", 2, 245-254 (2012)

21. V. B. Kogan Azeotropic and extractive rectification, (2-nd ed.), (Leningrad: Chemistry, 1971) 